\title{
STREPTOCEPHALUS SIRINDHORNAE, NEW SPECIES OF FRESHWATER FAIRY SHRIMP (ANOSTRACA) FROM THAILAND
}

\author{
La-orsri Sanoamuang, Gopal Murugan, \\ Peter H. H. Weekers, and Henri J. Dumont
}

(LS) Department of Biology, Faculty of Science, Khon Kaen University, Khon Kaen 40002, Thailand; (GM, PHHW, HJD) Institute of Animal Ecology, University of Ghent, Ledeganckstraat, B-9000 Ghent, Belgium (corresponding author (HJD) e-mail: Henri.Dumont@rug.ac.be)

\section{A B S T R A C T}

Streptocephalus sirindhornae, new species, the first freshwater anostracan from Thailand, is widespread in the northeast of the country. It is morphologically closest to the Indian species $S$. dichotomus, but a sequence analysis of its SSU rDNA gene reveals that its closest relative is in fact the Indian species-pair $S$. dichotomus-S. simplex, that it is probably a conserved member of the $S$. dichotomus-group, and that it shares some relationship with the $S$. torvicornis-group.

The speciose genus Streptocephalus is widely distributed across North America, Africa, northern Europe, and, tenuously, extends into Australia. In the humid tropical parts of the Oriental area, it is distinctly less abundant. Five species occur across the Indian subcontinent (Bond, 1934; Belk and Esparza, 1995), of which only S. dichotomus (Baird) has been found a single time near Rangoon, Burma (currently Myanmar), possibly a manmediated introduction. On the island of Java, Indonesia, another species, $S$. javanensis Brehm, 1955, has been recorded by Vaas (1952) and described by Brehm (1955) (see comments by Belk and Brtek, 1995).

Here, we describe an additional new species from northeast Thailand, where it is remarkably widespread in episodic waters and has been recorded under the vernacular name "freshwater Artemia" by Serjkij (1989). The description is based on the type material and includes observations on morphology by optical and SEM microscopy, a molecular characterization of the species based on the full sequence of its SSU (18S) rDNA gene, and a phylogenetic positioning within the genus based on a comparison with related species.

\section{Streptocephalus sirindhornae, new species}

Material.-All specimens are preserved whole in an alcohol-glycerol mixture. Holotype: 1 mature male, $2 \mathrm{~km}$ north of Khon Kaen University Campus, 7 June 1998 (L. Sanoamuang leg.), deposited in the British Museum (Natural History), accession number 1999.77. Paratypes, from the same collection as the holotype: 2 males, 2 females, deposited in the British Museum (Natural History), accession numbers $1999.75-76$ and 1999.78-79; 2 males,
2 females, deposited in the collection of the Royal Institute of Natural Sciences, Brussels, accession numbers IG 28.694 a-d; 2 males, 2 females, deposited in the Science Museum of Khon Kaen University, Thailand, accession numbers KKU-ANO 98001-98002.

Other Material. -2 females, 6 June 1993; numerous juveniles, 30 May 1998, temporary pond in Nong Bua Lam Phu province (water temperature $34^{\circ} \mathrm{C}, \mathrm{pH} 8.0$, conductivity $200 \mu \mathrm{S} \mathrm{cm}^{-1}$ ); 8 males, 29 females, temporary pond in Phon Pisai district, Nong Khai province (temperature $33.1^{\circ} \mathrm{C}, \mathrm{pH} 7.6$, conductivity $19 \mu \mathrm{S} \mathrm{cm}^{-1}$ ).

Type Locality.-An unnamed temporary pond in Ban Non Muang subdistrict, approximately $2 \mathrm{~km}$ from the north end of Khon Kaen University, Khon Kaen province. On 7 June 1998 (date when the type series was collected), the aquatic environment was characterized by: temperature $34.5^{\circ} \mathrm{C}$, pH 6.6 , conductivity 170 $\mu \mathrm{S} \mathrm{cm}^{-1}$, dissolved oxygen $5.6 \mathrm{mg} \mathrm{l}^{-1}$, turbidity 313 NTU.

Etymology.-The new species is named in honor of H.R.H. Princess Maha Chakri Sirindhorn of Thailand.

Diagnosis.-Male. Prehensile antenna with 3 or 4 fleshy processes and 10-12 slender processes. Hand with deeply bifid finger. Hand not broadened at base of thumb. Spur knife-shaped, not constricted apically. Margin of lower finger undulate along distal third. Upper finger pustulate, apically divided into 2 digits of unequal length. Both digits pustulate, shorter one with upturned apex. Wart at foot of apical joint.

Female. Habitus as in $S$. dichotomus, including elongated brood pouch. Cyst spheri- 


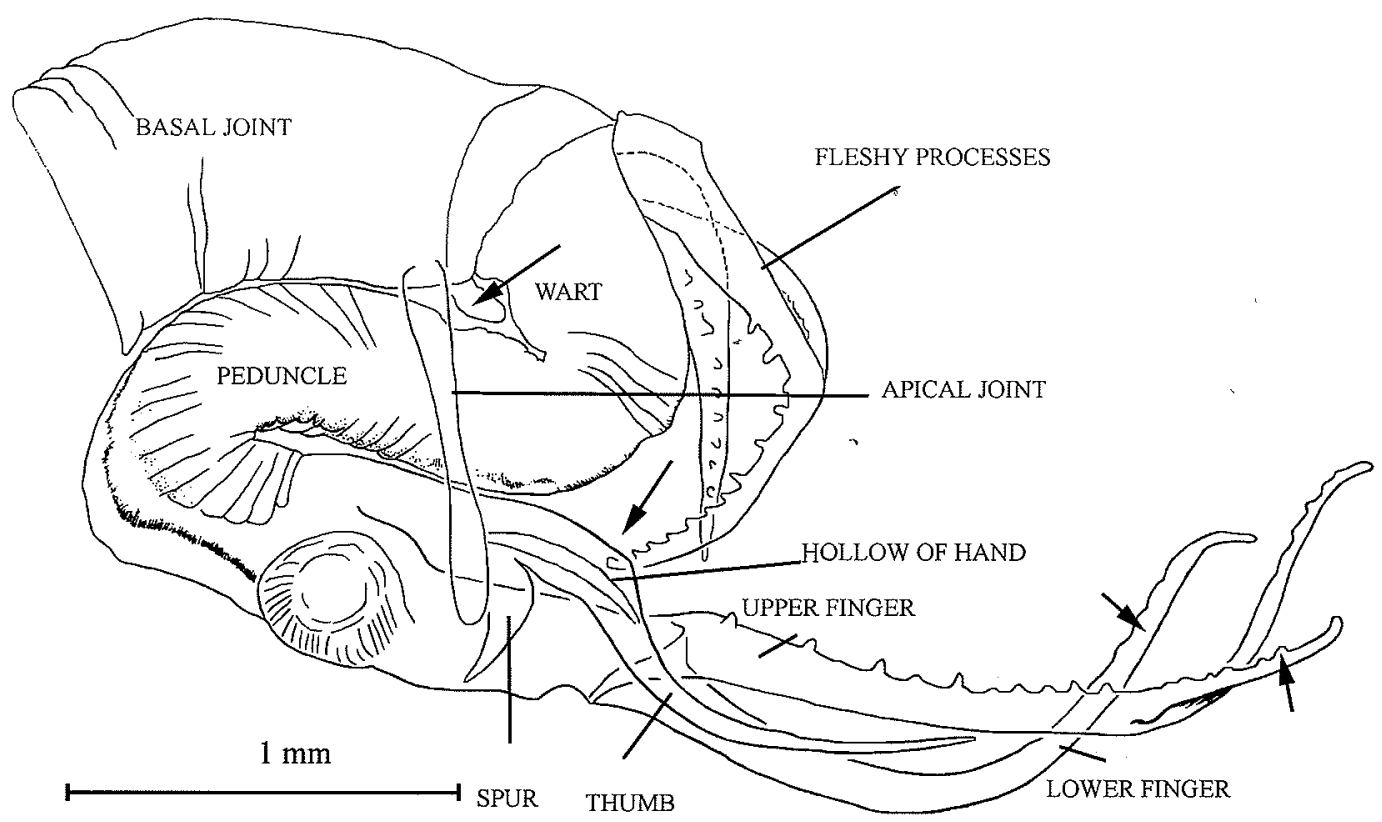

Fig. 1. Streptocephalus sirindhornae, new species, semidiagrammatic representation of the prehensile antenna of the male.

cal, surface sculptured with polygons of variable size and shape. Cyst wall with alveolar layer as in $S$. dichotomus, but inner layer less well demarcated.

Both sexes. SSU (18S) rDNA gene 1,806 bp long (A 452, C 410, G 495, T 441). GC content thus $50.55 \%$. Gene more conserved than in $S$. dichotomus and $S$. simplex Gurney, 1906, i.e., without a T/C and an A/G substitution in positions 1,364 and 1,374 , but sharing a C/A substitution in position 241 with $S$. dichotomus s.s.

Description.-Male. Average total length (from front of head to tip of telson between cercopods) $16.6 \mathrm{~mm}(n=20)$, range $15-18$ $\mathrm{mm}$. First antenna filiform. Second antenna strongly developed, with peduncle of distal outgrowth of elongate type (sensu MaedaMartinez et al., 1995). Distinct outgrowth (wart) medial to basis of apical joint. Fleshy processes at tip of medial process well developed, covered with pustulations on underside, 3-5 in number (Fig. 1, Fig. 2: 1-6). Peduncle with 10-12 slender processes, inserting on both sides of the inflexion (Fig. 1, Fig. 2: 1, 2). Hand well developed, of $S$. dichotomus type. Thumb and spur totally devoid of spines, with well-developed hollow. Hand not broadened at base of thumb; apex of hand smoothly rounded, not extending beyond base of thumb. Thumb longer than half length of lower finger (Fig. 1, Fig. 2: 2). Spur broadly knife-shaped, not constricted apically. Finger long, deeply bifid. Upper (outer) finger with pustulations but no true spines all along. Apically, second bifurcation in two digits of unequal length, both pustulated, apex of shorter digit distinctly upturned (Fig. $2: 3,5,6)$. Longer digit less than twice length of shorter. Lower finger deeply curved, sharply keeled over most of length, apical third with undulating free margin.

Phyllopodia with gross structure as typical for genus. Endite 1 of fifth pair of limbs with filter comb and, at posterior side, with scraping spine and naked tactile seta (Fig. 3: 1-3). (Both probably genus-specific too, but have only been studied in detail in $S$. torvicornis (Waga, 1842). Spines on scraping seta of $S$. torvicornis finer and possibly more numerous (13 in fig. 4 of Mertens et al., 1991; 10 , and of stronger build in $S$. sirindhornae, see Fig. 3: 2)). Setules on filter comb about as long as diameter of setae (Fig. 3: 4) (minimum 1.5 times diameter of seta in S. torvicornis; no information on $S$. dichotomus available); setules smooth, not barbed. Genital segment and penes as in S. dichotomusgroup. Cercopods as in $S$. dichotomus. 

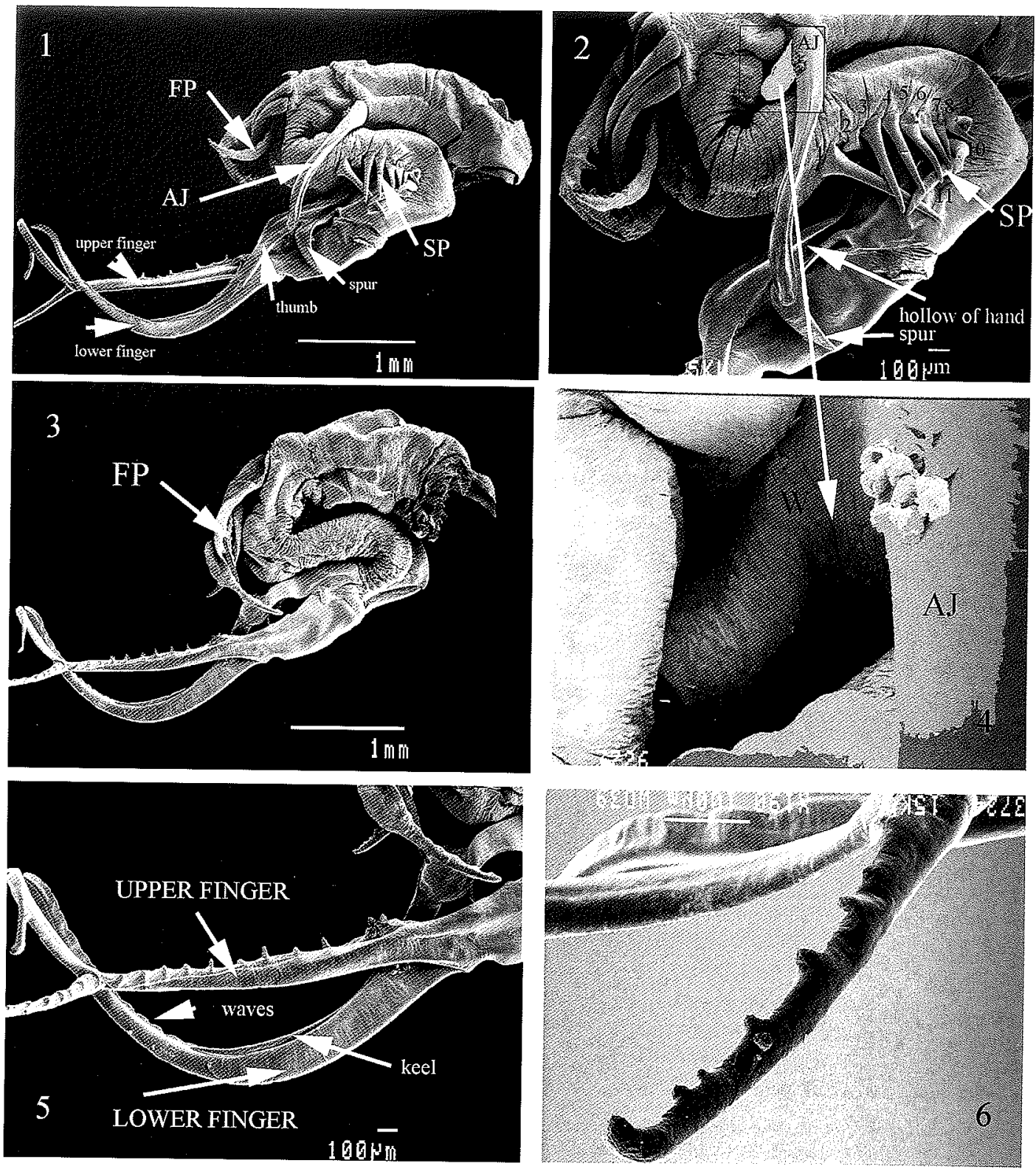

Fig. 2. Streptocephalus sirindhornae, new species, computer-edited SEM micrographs of male prehensile antenna. 1. External view; 2 . External view enlarged; 3 . Internal view; 4 . Enlargement, showing the wart at the base of the apical joint; 5 . Detail of upper and lower fingers; 6 . Shorter of the two digits of the upper finger. (AJ = apical joint, $\mathrm{FP}=$ fleshy process, $\mathrm{SP}=$ slender process.)

Female. Average total length $14.0 \mathrm{~mm}$ $(n=20)$, range $13-15 \mathrm{~mm}$. Antennule filiform. Antenna blade-shaped, as in $S$. dichotomus-group. Phyllopodia and cercopods as in male. Brood pouch elongate, fusiform. Cysts spherical, $0.2-0.24 \mathrm{~mm}$ in diameter. Outer surface polygonal, but pattern of polygons variable (Fig. 3: 5, 6 represents two cysts collected from females belonging to a single population). Cyst wall in cross section with alveolar layer with large lacunae, exactly as in $S$. dichotomus (cf. Figs. 1-3 of De Walsche et al., 1991). In contrast, so-called inner layer (Fig. 3: 7), well individualized in $S$. dichotomus, is not demarcated in S. sirindhornae. 


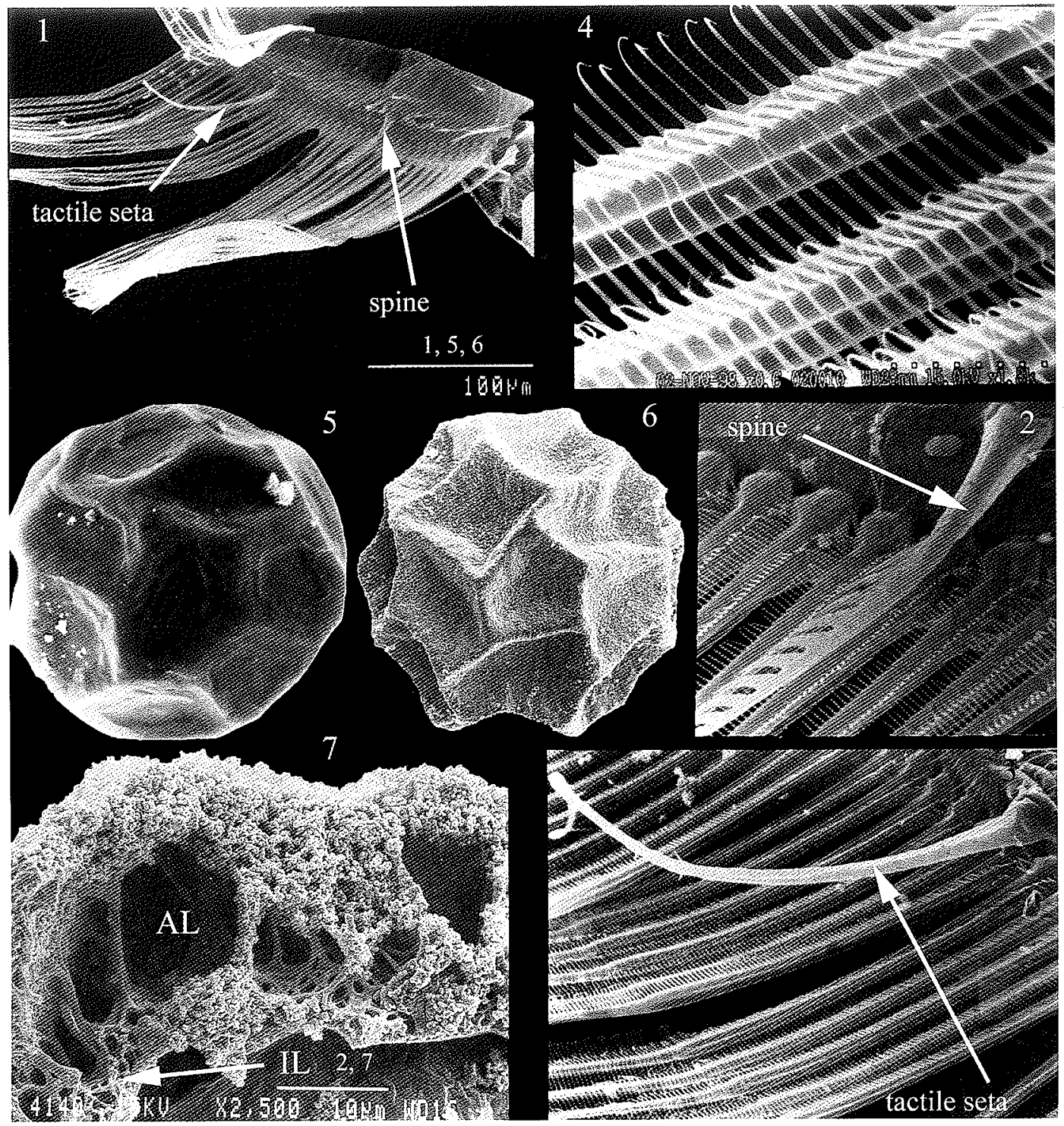

Fig. 3. Streptocephalus sirindhomae, new species, computer-edited SEMs. 1. Endite 1 of trunk limb 5, overview; 2. Spine on endite, enlarged; 3. Tactile seta on endite, enlarged; 4. Detail of setulation of the setae of endite $1 ; 5,6$. Two cysts taken from a single clutch, showing extreme forms of facets; 7 . Cross-section through a cyst. (AL = alveolar layer, $\mathrm{IL}=$ inner layer.)

Differential Diagnosis.-The species is morphologically closest to $S$. dichotomus. Males differ by the presence of a wart at the base of the apical joint of the prehensile antenna, by the presence of pustulations (not spines) on the fingers, and by the fact that the base of the thumb is not swollen as in S. dichotomus. The latter species may show considerable variation in some meristic characters. Radakrishna and Prasad (1976) considered this a sufficient basis to doubt the validity of some relatives of $S$. dichotomus (but see molecular information). In specimens from a laboratory culture of $S$. dichotomus (derived from dried mud collected from a pond bottom at Krishnagiri, Tamil Nadu, India), the spur is apically constricted, the hand is widened at the base of the thumb, the thumb is less than half the length of the lower finger, and the hand presents a rounded apical 


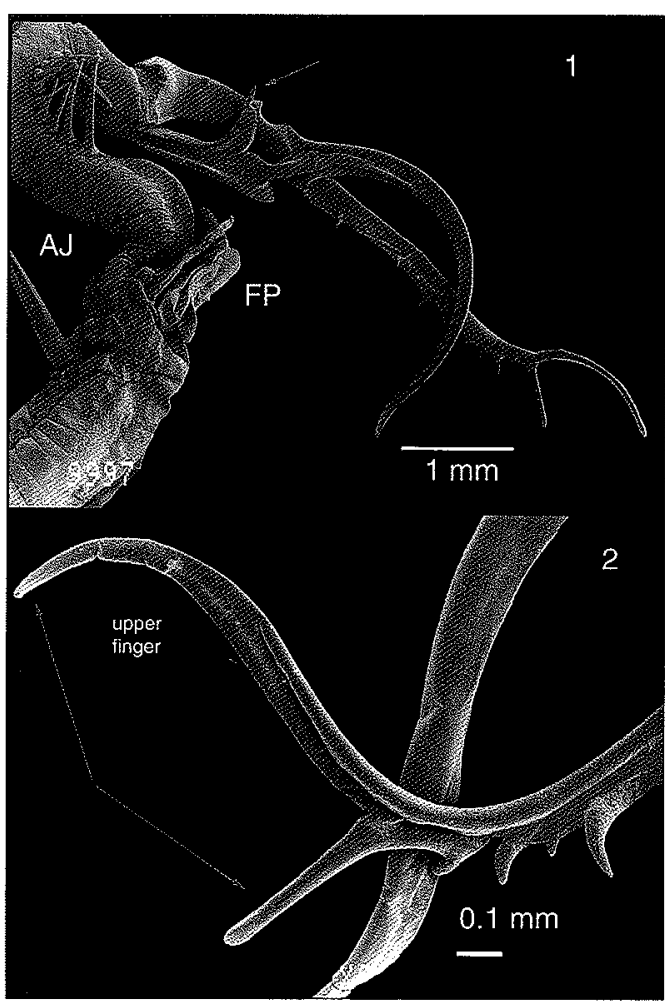

Fig. 4. Streptocephalus dichotomus (Baird), computeredited SEMs of male prehensile antenna. 1. Overview; 2. Apical zone of upper finger (abbreviations as in Fig. 2).

expansion at its tip (Fig. 4: 1). The fork at the apex of the upper finger, finally, is more strongly asymmetric than in $S$. sirindhornae, and its two digits are smooth, not pustulated (Fig. 4: 2). Specimens from the area of Madras (= Chennai), Tamil Nadu, figured by Sars (1900) only differ from these in having an unconstricted spur and sharp spines near to the tip of the upper finger, such that, in spite of some variation, it should be straightforward to tell $S$. sirindhornae apart from $S$. dichotomus, the main range of which appears to lie several thousands of kilometers further west. Females of both species are morphologically similar, but seem to differ in structure of the cyst wall (a non-demarcated vs. a demarcated inner layer), as seen in cross-sections (Fig. 4: 7).

\section{MOLECULAR INFORMATION}

Experimental Procedures. - Muscular tissue was isolated from the trunk and total DNA prepared according to the protocol of the Puregene ${ }^{\mathrm{TM}}$ DNA isolation kit, type D-5000A (BIOzym, Landgraaf, The Netherlands). The SSU IDNA (18S rDNA) was amplified by PCR, using Qiagen DNA polymerase (Westburg, Leusden, The Netherlands). Eukaryote-specific primers complementary to the $5^{\prime}$ terminus $\left(5^{\prime}\right.$-TACCTGGTTGATCCTGCCAG- $\left.3^{\prime}\right)$ and $3^{\prime}$ terminus (5'-TGATCCTTCCGCAGGTTCACCT-3') were used to amplify the entire SSU rDNA gene. Cycling conditions were $95^{\circ} \mathrm{C}$ for $1 \mathrm{~min}, 55^{\circ} \mathrm{C}$ for $1.5 \mathrm{~min}$ and $72^{\circ} \mathrm{C}$ for 2 min during 30 cycles. PCR products were sequenced directly according to the BigDye ${ }^{\mathrm{TM}}$ technique, the protocol of the $A B I$ Prism BigDye terminator cycle sequencing ready reaction kit, and analyzed on an $\mathrm{ABI}$ Prism 377 DNA sequencer (PE Applied Biosystems).

Sequence Data Alignment and Phylogenetic Analysis.The SSU rDNA sequences were aligned by eye, using the Eyeball Sequence Editor (ESEE) (Cabot and Beckenbach, 1989). Phylogenetic trees were constructed using parsimony (DNAPARS; PHYLIP package, Felsenstein, 1989), maximum likelihood (FastDNAml, Olsen et al., 1994), puzzle likelihood (PUZZLE, Strimmer and von Haeseler, $1996,1997)$, and neighbor-joining analysis on a distance matrix with distance values corrected according to Jukes and Cantor's one-parameter model (TREECON, Van de Peer and De Wachter, 1994). In all analyses, bootstrapping was performed to assess the stability of each branching point.

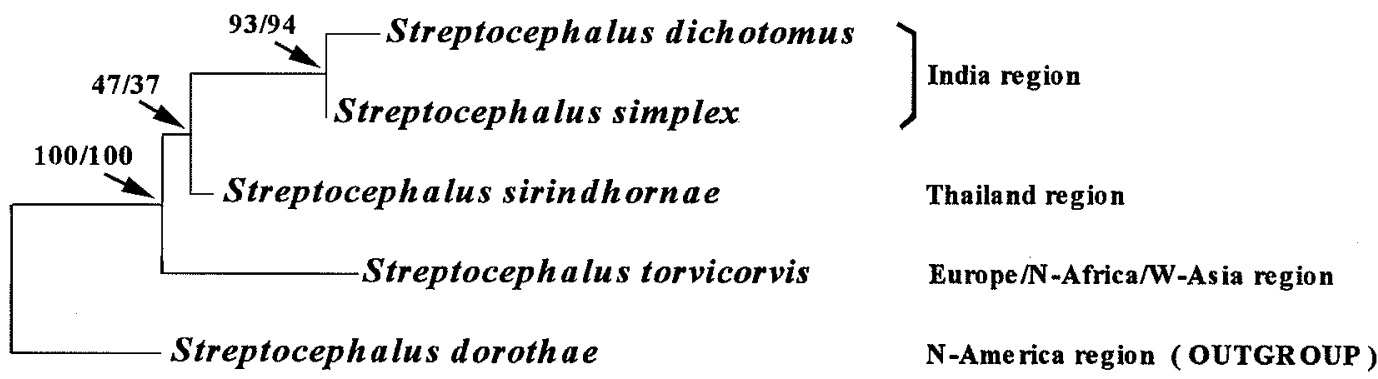

Fig. 5. Distance tree using the neighbor-joining method to show the phylogenetic position of Streptocephalus sirindhornae. The tree is rooted using $S$. dorothae as an outgroup. Numbers at the nodes give the number of times a cluster appeared in the consensus tree after a sequential bootstrap analysis of 100 runs in a distance analysis using neighbor-joining (first number) and parsimony (second number). 


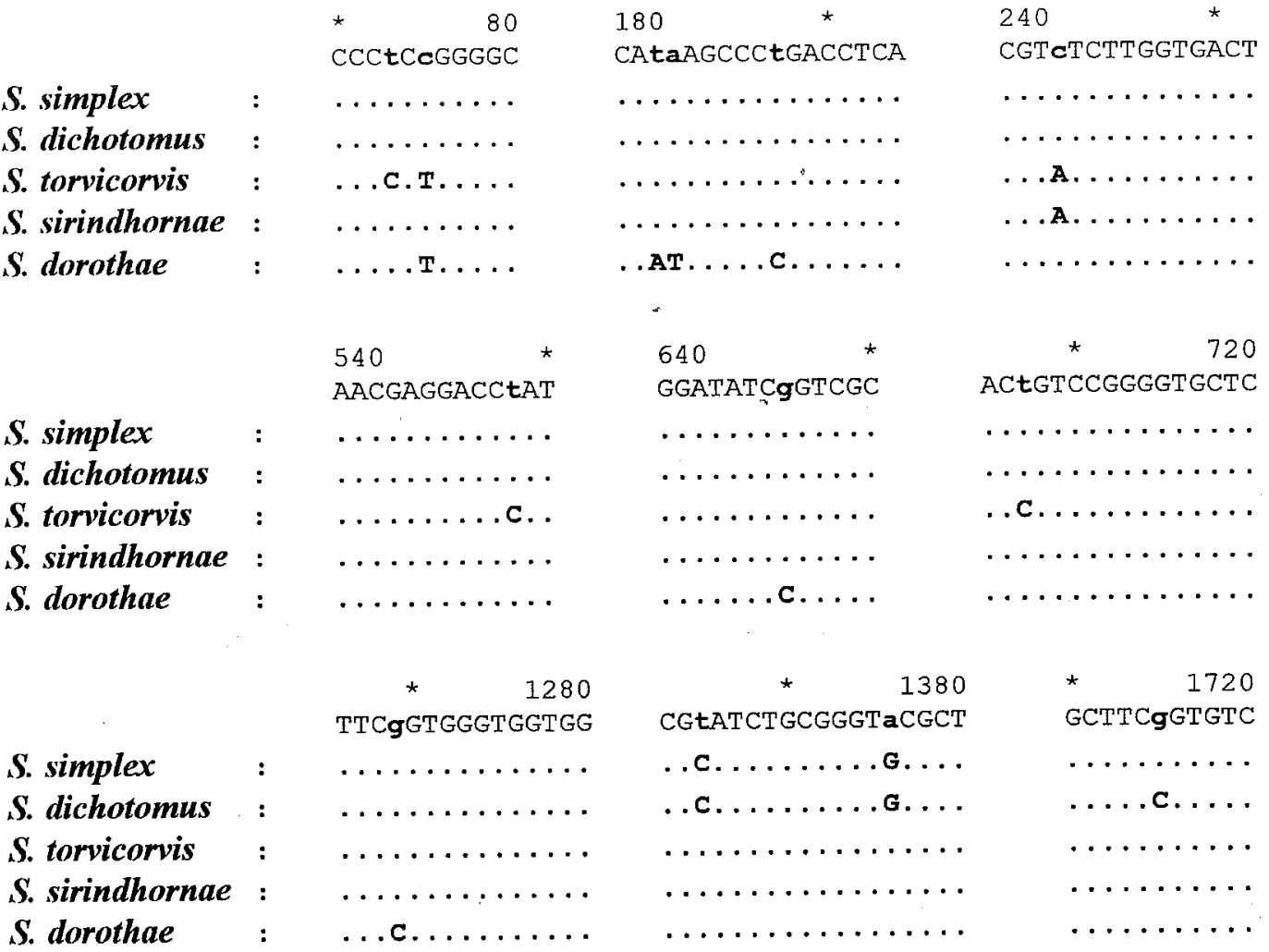

Fig. 6. Position of the variable sites in the SSU rDNA gene of Streptocephalus sirindhornae and four other Streptocephalus species. The consensus sequence is shown on top and the location in the gene is indicated by a number and an asterisk.

\section{RESULTS OF THE DNA STUDY}

We obtained the complete, unambiguous sequence for the SSU rDNA gene, not only of $S$. sirindhornae but of four more-or-less related congeners. The gene is 1,806 base pairs long, and its $\mathrm{G}+\mathrm{C}$ content varies between $50.55 \%$ (S. sirindhornae) and $50.72 \%$ $(S$. dichotomus). The sequence variation among the five species is $0.72 \%$, caused by 13 variable nucleotides in nine regions (Fig. 6 ). Phylogenetic analysis, using the methods described above, resulted in a tree, inferred from evolutionary distances in a distance matrix method (Fig. 5) and showed the same topology as the parsimony tree (not shown). The maximum likelihood and puzzle likelihood analysis tended to cluster $S$. sirindhornae with $S$. torvicornis, but the bootstrap support for this topology was inconclusive (trees not shown).

\section{GEOGRAPHIC DISTRIBUTION AND PHYLOGENETIC RELATIONSHIP}

Assuming that, supplementary to our 1ocality records, those for "freshwater Artemia" by Serjkij (1989) also pertain to $S$. sirindhornae, new species, we can conclude that this species is widely distributed in the temporary waters of northeast Thailand (see map, Fig. 7). It is an eastern vicariant to the Indian species of the $S$. dichotomus group, showing a particularly close affinity with $S$. dichotomus s.s. However, the phylogenetic tree of Fig. 5 shows that the latter species and $S$. simplex are even more closely related, suggesting a recent speciation event on Indian territory. Both indeed show two unique substitutions in positions $1,364(\mathrm{~T} / \mathrm{C})$ and $1,376(\mathrm{~A} / \mathrm{G})$ (Fig. 6) not shared by $S$. sirindhornae. The ancestral form of the $S$. dichotomus-group, therefore, 


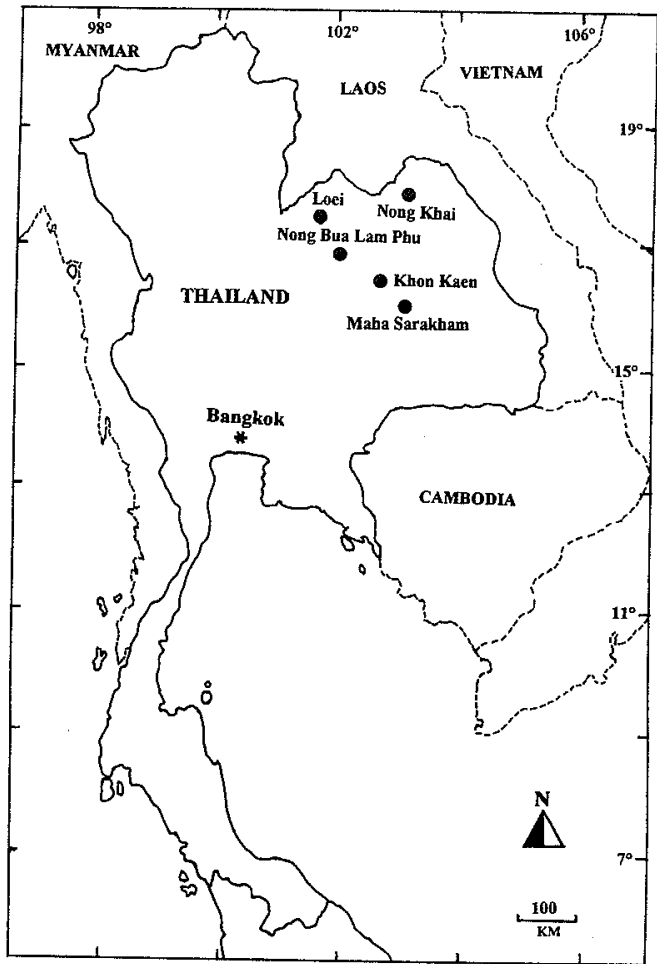

Fig. 7. The sites in northeast Thailand where $S$. sirind hornae has been collected.

probably had a branched antennal finger, a condition later lost in some Indian taxa. Streptocephalus sirindhornae, therefore, seems closer to that ancestral form than $S$. dichotomus itself. The dichotomus-group may have broken away from the $S$. torvicornis-group, the nominal species of which, S. torvicornis, shares one unique C/A substitution in position 241 with $S$. sirindhornae (Fig. 6), but more species and more genes should be studied to further test this idea. The torvicornis-group is currently widely distributed in Eurasia and Northern Africa. With S. dorothae Mackin, 1942, our outgroup representative of new-world streptocephalids, the relationship is even more remote, confirming the long isolation of this group, recently advocated by Maeda-Martinez et al. (1995).

\section{ACKNOWLEDGEMENTS}

Our thanks to Dr. H. Segers for help with SEM work and Mr. M. Bruyneel for photography. L. Sanoamuang was supported by the TRF/BIOTEC special program for Biodiversity Research and Training grant BRT 140028.

\section{Literature Cited}

Belk, D., and J. Brtek. 1995. Checklist of the Anostraca.-Hydrobiologia 298: 315-353.

- and C. E. Esparza. 1995. Anostraca of the Indian subcontinent.-Hydrobiologia 298: 287-293.

Bond, R. M. 1934. Report on Phyllopod Crustacea (Anostraca, Notostraca and Conchostraca) including a revision of the Anostraca of the Indian empire.-Memoirs of the Conneticut Academy of Arts and Sciences 10: $29-62$.

Brehm, V. 1955. Ein neuer Streptocephalus aus Indonesien (Streptocephalus javanensis n.sp.).-Sitzungsberichte der Osterreichische. Akademie der Wissenschaften, Abt. 1, 164: 249-254.

Cabot, E. L., and A. T. Beckenbach. 1989. Simultaneous editing of multiple nucleic acid and protein sequences with ESEE.-Computer Applications in Biosciences 55: 233, 234

De Walsche, C., N. Munuswamy, and H. J. Dumont. 1991. Structural differences in the cyst walls of Streptocephalus dichotomus (Baird), S. torvicornis (Waga) and Thamnocephalus platyurus (Packard) (Crustacea: Anostraca), and a comparison with other genera and species.-Hydrobiologia 212: 195-202.

Felsenstein, J. 1989. PHYLIP-Phylogeny inference package (Version 3.55c).-Cladistics 5: 164-166.

Maeda-Martinez, A., D. Belk, H. Obregon-Barboza, and H. J. Dumont. 1995. A contribution to the systematics of the Streptocephalidae (Branchiopoda : Anostraca).-Hydrobiologia 298: 203-232.

Martens, J., N. Munuswamy, C. De Walsche, and H. J. Dumont. 1991. The filtration apparatus of Anostraca (Crustacea): species-specific setulation in the genus Streptocephalus.-Hydrobiologia 212: 187-193.

Olsen, G. J., H. Matsuda, R. Hagstrom, and R. Overbeek. 1994. FastDNAml: a tool for construction of phylogenetic trees of DNA sequences using maximum likelihood.-Computer Applications in Biosciences 10: 41-48.

Radhakkrishna,Y., and M. K. D. Prasad. 1976. Anostraca (Crustacea: Branchiopoda) from Guntur district and its environs.-Memoirs of the Society of Zoology of Guntur 1: 79-87.

Sars, G. O. 1900. On some Indian Phyllopoda.-Cammermeyer, $29 \mathrm{pp} .+4 \mathrm{pl}$.

Serjkij, S. 1989. Freshwater Artemia.-House Agricultural Magazine 13: 86-77. [In Thai.]

Strimmer, K., and A. von Haeseler. 1996. Quartet puzzling; a quartet maximum likelihood method for reconstructing tree topologies.-Molecular Biology and Evolution 13: 964-969.

— and - 1997. Likelihood-mapping; a simple method to visualize phylogenetic content of a sequence alignment.-Proceedings of the National Academy of Sciences (USA) 94: 6815-6819.

Vaas, K. J. 1952. Merkwaardige lagere kreeften.-De Tropische Natuur 32: 131-133. [In Dutch.]

Van de Peer, Y., and R. De Wachter. 1994. TREECON for Windows: a software package for the construction and drawing of evolutionary trees for the Microsoft Windows environment.-Computer Applications in the Biosciences 10: 569, 570 .

RECEIVED: 22 February 1999. ACCEPTED: 8 February 2000 